\title{
Phase and Structural Study of Self-Doped $\mathrm{La}_{1-\mathrm{x}-\mathrm{y}} \mathrm{Ca}_{\mathrm{x}} \emptyset_{\mathrm{y}} \mathrm{MnO}_{3+\delta}$
}

\author{
F. Figueiras ${ }^{a}$, J.P. Araújo ${ }^{b}$, V.S. Amaral ${ }^{a}$, P.B. Tavares ${ }^{c}$, \\ A.B. LOPES ${ }^{d}$ AND J.M. VIEIRA ${ }^{d}$ \\ ${ }^{a}$ Departamento de Física and CICECO, Universidade de Aveiro \\ 3810-193 Aveiro, Portugal \\ ${ }^{b}$ Departamento de Física and IFIMUP, Universidade do Porto \\ 4169-007 Porto, Portugal \\ ${ }^{c}$ Departamento de Química and Centro de Qu!mica - Vila Real \\ Universidade de Trásos-Montes e Alto Douro, 5001-911 Vila Real, Portugal \\ ${ }^{d}$ Departamento de Engenharia Cerâmica e do Vidro and CICECO \\ Universidade de Aveiro, 3810-193 Aveiro, Portugal
}

To understand the combined effect of divalent ion and A-site vacancy $(\varnothing)$ self-doping, beyond the binary $\mathrm{La}_{1-x} \mathrm{MnO}_{3}$ system, polycrystalline $\mathrm{La}_{1-x-y} \mathrm{Ca}_{x} \varnothing_{y} \mathrm{MnO}_{3+\delta}$ samples were studied. Samples with Ca substitution and excess $\mathrm{Mn}$ in the range $x<0.33$ and $y<0.45$, respectively, were prepared by standard solid-state reactions. Structural and phase analysis of the samples were done by X-ray diffraction and transmission electron microscopy. The manganite structure in this composition range includes rhombic and orthorhombic phases. Most samples contain the hausmanite phase $\left(\mathrm{Mn}_{3} \mathrm{O}_{4}\right)$ coexisting with the manganite phase. A small amount of perovskite related $\mathrm{AMn}_{7} \mathrm{O}_{12}(\mathrm{~A}=\mathrm{La}, \mathrm{Ca})$ structure near the hausmanite-manganite boundary is also found in samples treated in oxygen atmosphere. The calculated vacancy content accommodated in the manganite phase can be higher than $1 / 8$, the reported limit for $\mathrm{La}_{1-x} \mathrm{MnO}_{3}$, which is confirmed in our $x=0$ sample. For the compositions studied, a ferromagnetic metallic behavior below $T_{\mathrm{C}}$ is found, confirming the stability of the Mn sublattice, and near the optimum stoichiometric $((x=0.33, y=0)$ system, a net A-site vacancy content (up to $y=0.2)$ does not degrade the magnetic and electric properties.

PACS numbers: $64.75 .+\mathrm{g}, 81.40 . \mathrm{Rs}, 75.50 .-\mathrm{y}, 72.20 . \mathrm{My}$

\section{Introduction}

Extensive research on colossal magnetoresistive lanthanum manganites has been performed on materials doped with divalent elements, with the general for- 
mula $\mathrm{La}_{1-x} \mathrm{~A}_{x} \mathrm{MnO}_{3}(\mathrm{~A}=\mathrm{Ca}, \mathrm{Sr}, \mathrm{Ba}, \mathrm{Pb})$, in search for optimized properties. Much less work has been directed to the study of self-doped manganites $\mathrm{La}_{1-x} \mathrm{MnO}_{3}$. The known studies show that La-deficient systems can be technologically interesting, reaching high ferromagnetic transition temperatures [1,2]. There is also raising interest also due to the fundamental problems of composition and structure correlation to the A-site vacancies [3-5]. In addition, thin films of $\mathrm{La}_{1-x} \mathrm{MnO}_{3}$ [6] and ( $\mathrm{La}, \mathrm{Ca})_{1-\infty} \mathrm{MnO}_{3}$ [7] prepared by MOCVD have shown Curie temperatures near 290-300 K with a high magnetoresistance ratio. One relevant issue for the study of these non-stoichiometric materials is the formation of secondary $\mathrm{Mn}$-rich phases, the main one being hausmanite $\mathrm{Mn}_{3} \mathrm{O}_{4}$, typically for La-deficiency above $\sim 10-12 \%[5,8]$. To address these issues and understand the role of A-site cationic vacancies $(\varnothing)$ beyond the binary $\mathrm{La}_{1-x} \mathrm{MnO}_{3}$ system, polycrystalline $\mathrm{La}_{1-x-y} \mathrm{Ca}_{x} \emptyset_{y} \mathrm{MnO}_{3+\delta}$ samples with excess $\mathrm{Mn}$ were prepared in the range $x<0.33$ and $y<0.45$ (see [9] for details).

\section{Composition, structure and phases of bulk samples}

Samples were prepared by standard solid-state reactions by repeatedly calcining and milling. The following final conditions were investigated: (a) cold pressed reacted powders sintered in air at $1300^{\circ} \mathrm{C}$ for $10 \mathrm{~h}$; those initial pellets (a) were further annealed at: (b) $1000^{\circ} \mathrm{C}$ for $24 \mathrm{~h}$ under flowing oxygen or (c) $1350^{\circ} \mathrm{C}$ in air for 60 hours. Chemical compositions were determined by atomic absorption spectroscopy (AAS), energy dispersion spectroscopy (EDS) in scanning electron microscope (SEM) and Rutherford backscattering spectrometry (RBS) techniques. Transmission electron microscopy (TEM) analysis was done to corroborate the $\mathrm{X}$-ray diffraction results. Thin sections for nano-analytical high resolution TEM were prepared by mechanically grinding following by precision ion milling with Ar ions. The elemental analysis was determined by using the nano-EDS gauge of diameters down to $4 \mathrm{~nm}$ in TEM.

Sample average global compositions plotted in the $x(\mathrm{Ca})-y(\emptyset)$ plane are shown in Fig. 1. The samples are divided into four sets accordingly to compositions: $y=4 x, y=1.5 x, y=0.4 x$, and $y=0$. The results reported will concentrate mostly on the samples labeled as 1 to 4 in Fig. 1.

The analysis of structure and phases of the samples was performed by X-ray diffraction (XRD) with Rietveld refinement and transmission electron microscopy. Electrical resistivity, magnetoresistance, a.c. magnetic susceptibility, and SQUID magnetization measurements were used to study the combined effect of Ca substitution and vacancy self-doping on the electrical and magnetic properties and are detailed elsewhere $[9,10]$. The manganite structure in the studied composition range includes rhombic and orthorhombic phases, coexisting in a mixed form in given ranges of the $x-y$ values. The XRD analysis readily reveals the presence of the hausmanite $\left(\mathrm{Mn}_{3} \mathrm{O}_{4}\right)$ phase in most samples. The relative content of $\mathrm{Mn}_{3} \mathrm{O}_{4}$ for 


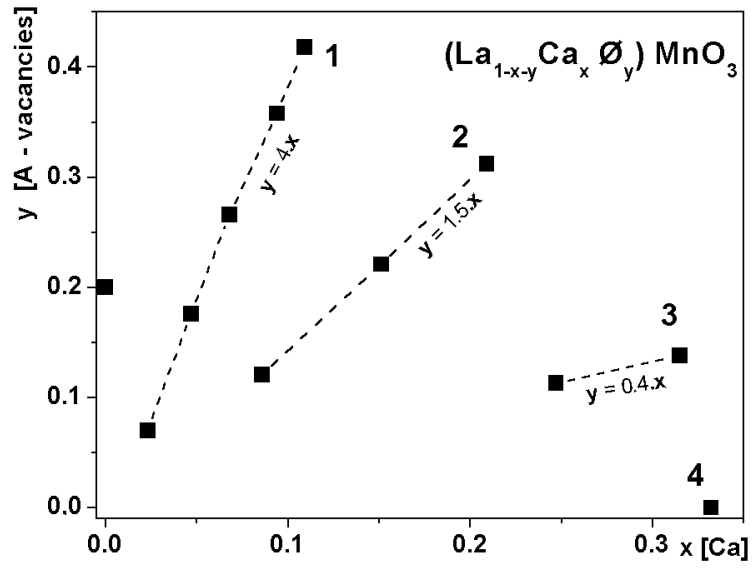

Fig. 1. Average composition of the samples plotted in the $x(\mathrm{Ca})-y(\varnothing)$ plane. Specific results for samples labeled 1-4 are reported in the text.

each sample was determined by the area ratio of the two main diffraction peaks of hausmanite and manganite phases with a previous calibration using known phase mixture powder samples. The amount of $\mathrm{Mn}_{3} \mathrm{O}_{4}$ increases with the stoichiometric deviation $y$ of the average global composition of the samples. The difference between the compositions of the manganite phase and the global composition of the sample increases with $y$. The reduction of $\mathrm{Mn}_{3} \mathrm{O}_{4}$ content is achieved by heat treatment of the initial pellets (a). It is found that the 24 hours treatment in $\mathrm{O}_{2}$ at $1000^{\circ} \mathrm{C}$ (b) is much more effective than the 60 hours treatment in air (c) at high temperature $\left(1350^{\circ} \mathrm{C}\right)$. However, heat treatment (b) does not necessarily lead to additional manganite phase formation. Given X-ray diffraction peaks are found, which cannot be attributed to the hausmanite or manganite phases.

The detailed analysis of the X-ray diffractograms of the samples in treatment (b), including Rietveld refinement shows that those extra peaks can be related to the perovskite based $\mathrm{Mn}$-rich $\mathrm{LaMn}_{7} \mathrm{O}_{12}$ phase. This phase (JCPDS data base reference \#27-0261) presents a monoclinic $P 2 / m$ structure with parameters: $a=7.516, b=7.376, c=7.516 \AA, \beta=91.30^{\circ}$. Figure 2 presents the data for sample 2 under treatment (b), normalized to the highest peak of the manganite phase. The vertical lines correspond to the $\mathrm{LaMn}_{7} \mathrm{O}_{12}$ phase. The arrows indicate two peaks that do not correspond to the two main phases. The overall $\mathrm{X}$-ray diffraction pattern of the $\mathrm{LaMn}_{7} \mathrm{O}_{12}$ phase is quite distinct from those of manganite or hausmanite, with very few peaks overlapping those of the major phases. At $2 \theta \approx 59.95$ one can recognize a peak convolution, between the plane (222) of the $\mathrm{LaMn}_{7} \mathrm{O}_{12}$ phase and (224) of the hausmanite. The presence of the $\mathrm{LaMn}_{7} \mathrm{O}_{12}$ phase is strongly dependent on the thermal treatment. With the exception of the stoichiometric sample $4\left(\mathrm{La}_{0.67} \mathrm{Ca}_{0.33} \mathrm{MnO}_{3+\delta}\right)$, the peak at $2 \theta \approx 55.15,(204)$ plane of the $\mathrm{LaMn}_{7} \mathrm{O}_{12}$ phase, is clearly observed in samples annealed at $1000^{\circ} \mathrm{C}$ 


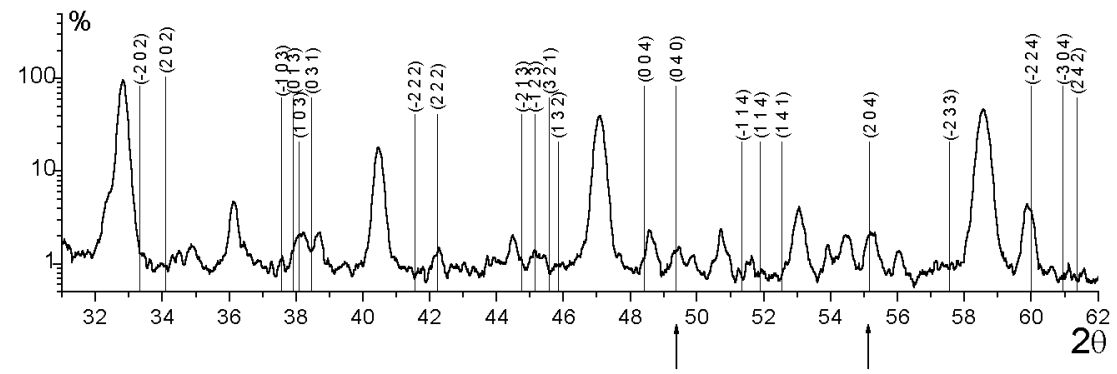

Fig. 2. X-ray diffractogram in logarithmic scale for sample 2 under treatment (b), normalized to the highest peak of the manganite phase. The vertical lines correspond to the $\mathrm{LaMn}_{7} \mathrm{O}_{12}$ phase. The arrows indicate two of the lines that are well separated from those of the manganite and hausmanite, the main phases.

for $24 \mathrm{~h} \mathrm{in} \mathrm{O}_{2}$ (treatment (b)) but it is hardly seen, or absent in the original (a) samples, or after further $60 \mathrm{~h}$ at $1350^{\circ} \mathrm{C}$ in air, heat treatment (c). This is shown in Fig. 3 for samples 2, 3 and 4 in correspondence with the heat treatments. The increase in $\mathrm{LaMn}_{7} \mathrm{O}_{12}$ phase peaks under thermal treatment follows the decreasing in hausmanite phase. The (204) peak of the $\mathrm{LaMn}_{7} \mathrm{O}_{12}$ phase, which is the most intense of the present samples is not one of the main peaks of the phase $(20 \%$

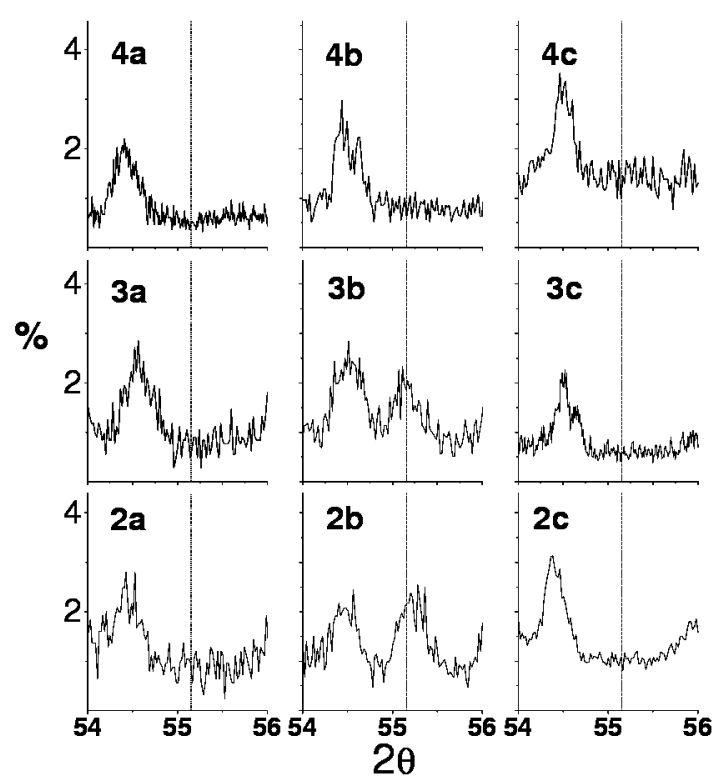

Fig. 3. Details of X-ray diffractograms near the $\mathrm{LaMn}_{7} \mathrm{O}_{12}$ (204) peak for samples 2, 3 , and 4 under the three heat treatments. With the exception of the stoichiometric sample 4 , the $\mathrm{LaMn}_{7} \mathrm{O}_{12}$ phase is clearly observed in the samples annealed at $1000^{\circ} \mathrm{C}$ for $24 \mathrm{~h}$ in $\mathrm{O}_{2}$ (heat treatment (b)) but it is hardly detected or absent in the original (a) samples or of heat treatment (c) $60 \mathrm{~h}$ at $1350^{\circ} \mathrm{C}$ in air. 
in JCPDS data base reference \#27-0261). In fact, the main characteristic peaks of the $\mathrm{LaMn}_{7} \mathrm{O}_{12}$ phase $((202)(100 \%),(202)(80 \%)$, and (304) (80\%)) are not significant. The (040), (004) and (2224) (all $80 \%$ intensity) peaks are detected, but at lower intensity than the (204) peak. This discrepancy is discussed below.

The synthesis of the pure $\mathrm{LaMn}_{7} \mathrm{O}_{12}$ compound demands high pressures and temperatures $\left(40 \mathrm{kbar}\right.$ and $1000^{\circ} \mathrm{C}$ ) due to the atypical coordination $\left(\mathrm{La}_{1 / 4} \mathrm{Mn}_{3 / 4}\right)^{\mathrm{A}}\left(\mathrm{Mn}_{1}\right)^{\mathrm{B}} \mathrm{O}_{3}$ in this perovskite structure. The favorable thermodynamic conditions for the nucleation of the $\mathrm{LaMn}_{7} \mathrm{O}_{12}$-like phases may also be locally achieved by epitaxial growth in thin films $\left(\mathrm{Nd}_{0.50} \mathrm{MnO}_{3+\delta}\right)$ [11] or at the grain boundaries during the manganite sintering. On the other hand, $\mathrm{CaMn}_{7} \mathrm{O}_{12}$ is also a perovskite-like compound but of hexagonal structure $R \overline{3}$, with $a=10.464 \AA$ and $c=6.343 \AA$. It can be prepared at normal atmospheric pressure [12]. Due to the smaller relative amount of $\mathrm{Ca}$ than $\mathrm{La}$ in samples $(x \geq 0.33)$, the fractional amount of this phase should be reduced.

Contrary to the case of hausmanite, the quantification of the $\mathrm{LaMn}_{7} \mathrm{O}_{12}$-like phase in the samples cannot be done in this study, since not all major peaks are visible and standards for this phase are not available. However, the area ratio between a $\mathrm{LaMn}_{7} \mathrm{O}_{12}$ peak and the main manganite peak still gives a rough indication of the relative content. For this estimate, the $(040)$ peak of $\mathrm{LaMn}_{7} \mathrm{O}_{12}$ at $2 \theta \approx 49.37^{\circ}$ ( $80 \%$ intensity) was selected as it is easily observed and appears in a properly isolated position on the diffractogram. The (224) peak (80\% intensity) is too close to the hausmanite (224) peak to be considered of any practical use, while the (204) peak (20\% intensity), should be less reliable for quantitative analysis. The relative content of the $\mathrm{LaMn}_{7} \mathrm{O}_{12}$ phase is always below $1.6 \%$, and it is below XRD detection resolution $(\sim 0.2 \%)$ for the original (a) samples and for the samples of heat treatment $(\mathrm{c})$. One finds that the $\mathrm{LaMn}_{7} \mathrm{O}_{12}$ phase content so determined is directly related to the reduction of the hausmanite phase content after the oxygen treatment (b), as shown in Fig. 4.

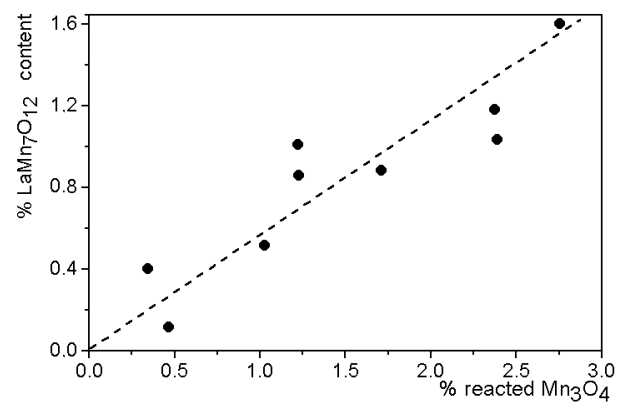

Fig. 4. Relation of the $\mathrm{LaMn}_{7} \mathrm{O}_{12}$ phase content with the reduction of the hausmanite phase content after the heat treatment under oxygen (b). 
TABLE

Properties of samples 2,3 , and 4 for the three thermal treatment conditions, including data on structural, magnetic, and transport properties. $M R$ is the low-field magnetoresistance.

\begin{tabular}{c|c|c|c|c|c|c|c|c}
\hline \hline Sample & $\begin{array}{c}T_{\mathrm{C}} \\
(\mathrm{K})\end{array}$ & $\begin{array}{c}M R \\
(\% / \text { Tesla })\end{array}$ & $\begin{array}{c}x^{\prime \prime} \\
(\mathrm{Ca})\end{array}$ & $\begin{array}{c}y^{\prime \prime} \\
(\varnothing)\end{array}$ & $\begin{array}{c}a \\
(\AA)\end{array}$ & $\begin{array}{c}b \\
(\AA)\end{array}$ & $\begin{array}{c}c \\
(\AA)\end{array}$ & $\begin{array}{c}\text { Vol. } \\
\left(\AA^{3}\right)\end{array}$ \\
\hline $4 \mathrm{a}$ & 263.5 & 34 & 0.336 & 0.013 & 5.460 & 5.474 & 7.697 & 230.0 \\
$4 \mathrm{~b}$ & 268.5 & 44 & 0.336 & 0.011 & 5.460 & 5.470 & 7.697 & 229.9 \\
$4 \mathrm{c}$ & 262 & 36 & 0.332 & 0 & 5.457 & 5.472 & 7.705 & 230.1 \\
$2 \mathrm{a}$ & 262 & 44 & 0.246 & 0.192 & 5.456 & 5.571 & 7.731 & 235.0 \\
$2 \mathrm{~b}$ & 265 & 47 & 0.227 & 0.254 & 5.465 & 5.556 & 7.732 & 234.8 \\
$2 \mathrm{c}$ & 262 & 44 & 0.241 & 0.206 & 5.473 & 5.564 & 7.751 & 236.0 \\
$3 \mathrm{a}$ & 266.5 & 44 & 0.334 & 0.086 & 5.446 & 5.495 & 7.697 & 230.4 \\
$3 \mathrm{~b}$ & 267 & 44 & 0.324 & 0.114 & 5.460 & 5.470 & 7.693 & 229.7 \\
$3 \mathrm{c}$ & 266 & 54 & 0.331 & 0.095 & 5.467 & 5.475 & 7.694 & 230.3
\end{tabular}

The consistency of these results allows one to finally set the composition of the major manganite phase, leading to the effective $A$-site vacancy content $\left(y^{\prime \prime}\right)$. For simplicity, we assume that the $\mathrm{La} / \mathrm{Ca}$ ratio in the $\mathrm{LaMn}_{7} \mathrm{O}_{12}$-like phase is the same as in the main material. In Table we present the calculated composition of the manganite phase of samples 2, 3, and 4, for the three thermal treatment conditions, along with data on structural, magnetic, and transport properties [9, 10]. The vacancy content $\left(y^{\prime \prime}\right)$ of the manganite phase is plotted in Fig. 5 , as a function of the

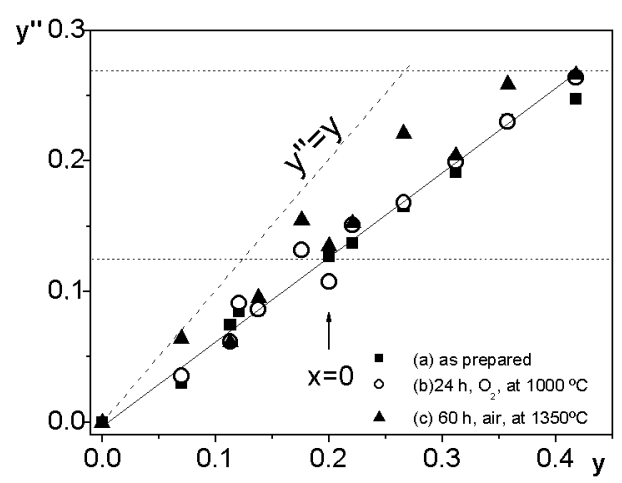

Fig. 5. The vacancy content ( $\left.y^{\prime \prime}\right)$ of the manganite phase determined from X-ray diffraction as a function of the value of the original average $(y)$. The manganite phase accommodates a large fraction of vacancies, up to the solid solution limit close to $y^{\prime \prime} \sim 0.27$ (line). This value is beyond the reported limit of $y=0.12$ for $\mathrm{La}_{1-y} \mathrm{MnO}_{3}[5,8]$, which is also confirmed by the $x=0$ composition of this study. 
original value $(y)$ in the sample average composition showing that the manganite phase accommodates a large fraction of vacancies. It is important to note that when $\mathrm{Ca}$ is present $(x>0) y^{\prime \prime}$ reaches values beyond $1 / 8$, the reported limit for $\mathrm{La}_{1-y} \mathrm{MnO}_{3}[5,8]$, which is confirmed for the $x=0$ composition of this study.

\section{Nano-EDS-TEM studies}

Results of HRTEM thin sections of samples 1 and 2 after heat treatment (c) and (b), respectively, are briefly described. Sample $2 \mathrm{~b}$ has an average composition of $\mathrm{La}_{0.479} \mathrm{Ca}_{0.209} \emptyset_{0.312} \mathrm{MnO}_{3+\delta}$. Sample $1 \mathrm{c}$ of average composition of $\mathrm{La}_{0.473} \mathrm{Ca}_{0.094} \emptyset_{0.433} \mathrm{MnO}_{3+\delta}$ has a lower $\mathrm{Ca}$ content. Both samples revealed an unreacted $\mathrm{Mn}_{3} \mathrm{O}_{4}$ hausmanite phase. The nano-EDS-TEM analysis of particles in

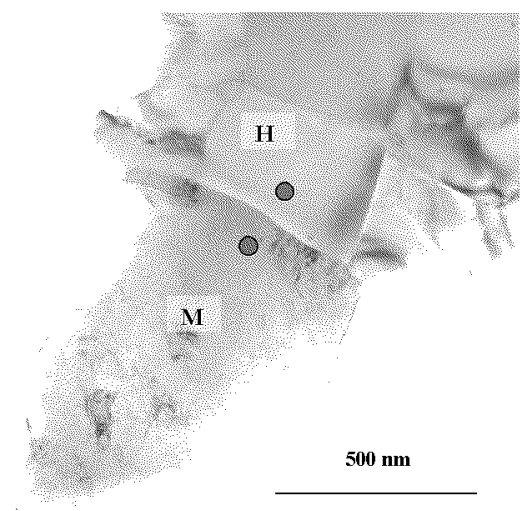

Fig. 6. Bright field TEM image of manganite $(M)$ particle and residual hausmanite $(H)$ particle of sample $2 \mathbf{b}, \mathrm{O}_{2}$ annealed. The composition as determined by nano-EDS analysis in TEM near the phase grain boundary (•) is: $\mathrm{La}_{0.51} \mathrm{Ca}_{0.21} \emptyset_{0.27} \mathrm{MnO}_{3+\delta}$ for the vacancy doped $(\mathrm{La}, \mathrm{Ca})$ manganite and $\left(\mathrm{Mn}_{0.986} \mathrm{La}_{0.011} \mathrm{Ca}_{0.003}\right)_{3} \mathrm{O}_{4}$ for the hausmanite solid solution.

contact with unreacted hausmanite particles in sample 2b (see Fig. 6) revealed local arrangements of particles of the following types:

(i) the hausmanite particle contacts manganite particles of ternary composition close to the average composition of the sample;

(ii) at places of La content below La sample average content, particles of chemical composition close to the binary phases $\mathrm{CaMn}_{3} \mathrm{O}_{7}$ (JCPDS \#19-0232), $\mathrm{CaMn}_{4} \mathrm{O}_{7}$ (JCPDS \#19-0233) with $\mathrm{La} /(\mathrm{La}+\mathrm{Ca}+\mathrm{Mn})$ content below $5 \%$ atm were observed;

(iii) at places of $\mathrm{Ca}$ content below Ca sample average content, particles of chemical composition close to the binary phases $\mathrm{LaMn}_{4} \mathrm{O}_{7}, \mathrm{LaMn}_{7} \mathrm{O}_{12}$ (JCPDS 
\#27-0261) with $\mathrm{Ca} /(\mathrm{Ca}+\mathrm{La}+\mathrm{Mn})$ content ranging from 2-5\% atm and particles of the nearly binary manganite phase with composition up to the solid solution limit of $\mathrm{La}_{0.598} \mathrm{Ca}_{0.070} \varnothing_{0.331} \mathrm{MnO}_{3+d}$ were found.

The arrangement (i) is more frequently observed.

A similar study of sample $1 \mathrm{c}$ showed that the composition profile of the manganite particles in contact with the hausmanite residual particles is constant from the phase boundary to the center of the particles, being approximately given as $\mathrm{La}_{0.607} \mathrm{Ca}_{0.121} \varnothing_{0.272} \mathrm{MnO}_{3+\delta}$.

The maximum value of A-site vacancy content in the manganite particles as determined by the nano-EDS analysis of TEM is close to $y=0.30$ for values of $\mathrm{Ca} / \mathrm{La}$ site occupation ranging from $x=0.07$ up to $x=0.30$. Fine particles (40-70 $\mathrm{nm}$ particle diameter) of $\mathrm{Mn}$ rich phases of the La-Mn-O system, namely the ( $\mathrm{La}, \mathrm{Ca}) \mathrm{Mn}_{4} \mathrm{O}_{7}$ and the $(\mathrm{La}, \mathrm{Ca}) \mathrm{Mn}_{7} \mathrm{O}_{12}$ solid solutions, are observed at contact or very close to unreacted hausmanite particles. The observation of $\mathrm{Mn}$ rich binary phases of the $\mathrm{Ca}-\mathrm{Mn}-\mathrm{O}$ system was anticipated from the published works [11] and is related to heterogeneity of mixture of the solid precursors of the samples in the present study.

\section{Discussion and conclusion}

Due to the manganese excess in the solid solution $(y>0)$, we can consider this element to assume a balanced distribution in the sample. The local environment for oxygen capture and type A cation diffusion will lead to the different phase distributions. The thermodynamic conditions created by sample processing and heat treatment lead mainly to the manganite phase formation. The eventual formation of B-site ( $\mathrm{Mn}$ ) vacancies above thermodynamic equilibrium concentration by the effect of oxygen intake would be easily filled by the surplus $\mathrm{Mn}$ in solution in metastable structures of the phase, or even from the contact with the Mn source, the hausmanite. One therefore expects that the Mn-site occupancy in the manganite phase can be taken very close to unity $\left[\emptyset_{\mathrm{B}}\right] \approx 0$, the related concentration of $\mathrm{A}$-site vacancies being not much compromised if the oxygen stoichiometry is not exactly 3 . The annealing step after sintering will extend the diffusion effect on the chemical species; specially of $\mathrm{Ca}$ and $\mathrm{La}$ cations that are eventually concentrated in incompletely reacted phases. At the sudden end of heat treatment, reactions may freeze in metastable phases, and some inhomogeneity of composition and crystallinity is expected. The stability of the Mn-site sublattice for the compositions studied is confirmed by the fact that all the samples show a ferromagnetic metallic behavior below the Curie temperature $\left(T_{\mathrm{C}}\right)$, which ranges from $220 \mathrm{~K}$ up to about $270 \mathrm{~K}[9,10]$. Moreover, as given in the Table, samples 2 and 3 , with vacancy contents $y^{\prime \prime} \sim 0.2$ and $\sim 0.1$, respectively, present a $T_{\mathrm{C}}$ value close to the stoichiometric sample $4\left(\mathrm{La}_{0.67} \mathrm{Ca}_{0.33} \mathrm{MnO}_{3+\delta}\right)$, and the presence of A-site vacancies even leads to an increase in magnetoresistance values. 
The estimate of A-site vacancy concentration for the manganite phase surpasses the maximum reported $(\sim 12 \%)$ for the $\mathrm{La}-\mathrm{MnO}_{3}$ phase $[5,8]$. The formation of intermediary phases from the manganite to the hausmanite regulates the amount of Mn that goes into solid solution and A-site vacancies. In Fig. 5, the limiting value for $y^{\prime \prime}$ in the manganite structure seems close to $\sim 27 \%$, which is also the manganite solid solution limit found by nano-EDS in TEM within error limits. The smples heat treated at $1350^{\circ} \mathrm{C}$ for $60 \mathrm{~h}$ in air (c) show a more effective incorporation of the manganese into manganite phase and a lack of $\mathrm{LaMn}_{7} \mathrm{O}_{12}$ phase, possibly due to the higher reaction temperature. The accommodation of such large amount of A-site vacancies (above 12\%) leads to a strong lattice distortion of the manganite phase. Such orthorhombic cell distortion is characterized by the increase in cell volume, keeping the shorter a lattice parameter constant, and increasing $b$ and $c$ [10].

The observed distribution of XRD peak intensities of the $\mathrm{LaMn}_{7} \mathrm{O}_{12}$ phase is different from that reported for bulk samples [JCPDS \#27-0261]. The $\mathrm{LaMn}_{7} \mathrm{O}_{12}{ }^{-}$ -like phase has an intermediate chemical composition between the $\mathrm{Mn}_{3} \mathrm{O}_{4}$ and the manganite $\mathrm{La}_{1-x-y} \mathrm{Ca}_{x} \varnothing_{y} \mathrm{MnO}_{3+\delta}$, and in favorable thermodynamic conditions, is a metastable transition phase during the reaction. The reaction process in which the hausmanite is decreased consists in oxidation, along with $\mathrm{Ca}$ and La cation incorporation originated through diffusion from the manganite surroundings. This process occurs in a limited active zone contacting the hausmanite grain boundaries, the thickness of the active zone being defined by the penetration diffusion length of the ions. A layered reaction zone around the hausmanite grains can lead to anisotropic $\mathrm{LaMn}_{7} \mathrm{O}_{12}$ growth with preferred orientations such as (204) or (224) determined by contact with the hausmanite crystals. It would be similar to the X-ray diffractograms of epitaxial thin films, where the intensity of the non-oriented peaks is reduced.

By applying the Scherrer formula to the isolated (204) peak of $\mathrm{LaMn}_{7} \mathrm{O}_{12}$ the width of the $\mathrm{LaMn}_{7} \mathrm{O}_{12}$ layer is estimated as $\langle D\rangle \sim 300 \AA$, or a layer thickness of approximately 200 atomic layers in the $(204)$ direction $\left(d_{(204)}=1.6001 \AA\right)$. This result, supported by TEM observation, explains the reduced amount of other crystalline planes and anomalous X-ray peak intensity distribution for the $\mathrm{LaMn}_{7} \mathrm{O}_{12}$. On the other hand, one notes that the X-ray diffraction of the (204) planes is not sensitive to the occupation element in the central A-site of the double perovskite cell of $\mathrm{LaMn}_{7} \mathrm{O}_{12}$. A disordered structure for the double perovskite A-site, with random occupancy by $\mathrm{La}, \mathrm{Ca}, \mathrm{Mn}$ and vacancies might lead to a severe reduction of the other plane XRD peaks and a XRD pattern different from the ordered cation distribution structure.

\section{Acknowledgments}

The work was supported by FCT under Project POCTI/CTM/35462/00. 


\section{References}

[1] A. Maignan, C. Michel, M. Hervieu, B. Raveau, Solid State Commun. 101, 277 (1997).

[2] T.R. McGuire, A. Gupta, P.R. Duncombe, M. Rupp, J.Z. Sun, R.B. Laibowitz, W.J. Gallagher, Gang Xiao, J. Appl. Phys. 79, 4549 (1996).

[3] J.A.M. van Roosmalen, P. van Vlaanderen, E.H.P. Cordfunke, W.L. IJdo, D.J.W. IJdo, J. Solid State Chem. 114, 516 (1995).

[4] J. Töpfer, J.B. Goodenough, Chem. Mater. 9, 1467 (1997).

[5] G. Dezanneau, A. Sin, H. Roussel, H. Vincent, M. Audier, Solid State Commun. 121, 133 (2002).

[6] S. Pignard, H. Vincent, J.P. Sénateur, J. Pierre, A. Abrutis, J. Appl. Phys. 82, 4445 (1997).

[7] P.B. Tavares, V.S. Amaral, J.P. Araújo, J.B. Sousa, A.A.C.S. Lourenço, J.M. Vieira, J. Appl. Phys. 85, 5411 (1999)

[8] P.A. Joy, C. Raj Sankar, S.K. Date, J. Phys., Condens. Matter 14, L663 (2002).

[9] J.P. Araújo, V.S. Amaral, P.B. Tavares, F. Lencart-Silva, A.A.C.S. Lourenço, J.B. Sousa, J.M. Vieira, J. Magn. Magn. Mater. 226-230, 821 (2001).

[10] F. Figueiras et al., to be published in J. Magn. Magn. Mater.

[11] A.A. Bosak, O.Yu. Gorbenko, A.R. Kaul, I.E. Graboy, C. Dubourdieu, J.P. Senateur, H.W. Zandbergen, J. Magn. Magn. Mater. 211, 61 (2000).

[12] B. Bochu, J.L. Buevoz, J. Chenavaz, A. Collomb, J.C. Joubert, M. Marezio, Solid State Commun. 36, 133 (1980). 